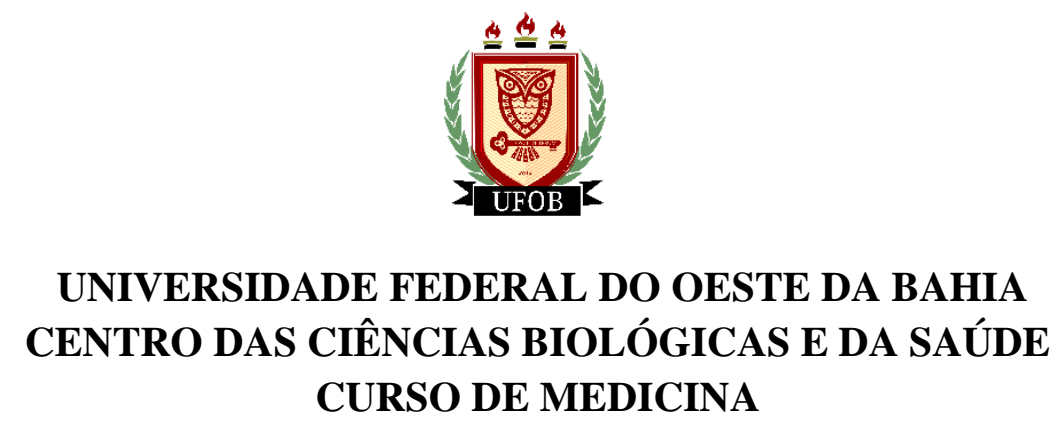

CURSO DE MEDICINA

ALIALDO DANTAS DAMASCENA

ADESÃO À PROFILAXIA PRÉ-EXPOSIÇÃO (PREP) ORAL ENTRE JOVENS: UMA REVISÃO SISTEMÁTICA 
ALIALDO DANTAS DAMASCENA

\title{
ADESÃO À PROFILAXIA PRÉ-EXPOSIÇÃO (PREP) ORAL ENTRE JOVENS: UMA REVISÃO SISTEMÁTICA
}

\author{
Monografia apresentada como requisito para \\ conclusão do componente TCC II do curso de \\ Medicina da Universidade Federal do Oeste da \\ Bahia. \\ Orientador: Prof. Me. Murillo da Silva Neto \\ Co-orientador: Prof. Dr. Marcos Pereira Santos
}




\section{DEDICATÓRIA}

À Dra. Linda Laubenstein, por abrir os caminhos para todos os nossos trabalhos envolvendo HIV desde os anos 80. 


\section{AGRADECIMENTOS}

Gostaria de iniciar agradecendo a Deus, inteligência suprema, causa primária de todas as coisas, por me permitir chegar até aqui na caminhada da minha vida pessoal e acadêmica, assim como agradeço a todos os amigos da espiritualidade que estiveram e estão do meu lado para que o melhor sempre aconteça.

Agradeço a meus pais, Alialdo e Conceição, por me forjarem e me fortalecerem em todos os momentos, me lembrando sempre das minhas responsabilidades $e$ capacidades, me apoiando sempre nas escolhas necessárias.

À minha irmã Caroline, por ser meu primeiro exemplo e me inspirar na minha caminhada a seguir os seus passos, cada um deles dado com excelência e por todos os momentos em que esteve lá por mim nas minhas necessidades.

Aos amigos que me acompanham desde antes dessa jornada começar, mas sem duvidar de mim um momento sequer: Pablo, Camile, Mariana, Gledy, João. À Camilla, por ouvir os choros, as reclamações, os risos e me acompanhar do início do sonho até agora.

Para aqueles que Barreiras me trouxe, não tenho palavras para agradecer o amor que demonstram por mim e pelo sentimento de família que pudemos construir. Fernando e Ana pela fraternidade, Lisiane por todas as histórias que pudemos juntos compartilhar e escrever, rir e chorar. Adriana, por toda a paciência e madrugadas de longas conversas e Apriscla, que primeiro me recebeu desde que pisei pela primeira vez na Universidade, por todos os chocolates, abraços, drinks, ciúmes e por todas as noites em que me abrigou no colchão de casa, nos horários mais imprevisíveis.

Por fim e não menos importante, agradeço ao professor Marcos Pereira Santos, por toda a sua espontaneidade para comigo desde o começo, por me acolher no meu momento de agonia e por possibilitar que esse trabalho fosse realizado, rumo à conclusão de mais uma etapa acadêmica, assim como o professor Murillo da Silva Neto, pela amizade, por aceitar o desafio de orientar o desconhecido e por também segurar a luz que me guia nessa estrada que apenas se inicia.

A cada um de vocês, meu eterno reconhecimento e gratidão. Amo-os para sempre. 


\section{RESUMO}

A Profilaxia Pré-Exposição - PrEP é uma forma de terapia medicamentosa liberada no ano de 2012, nos Estados Unidos, como forma de prevenir novas infecções pelo vírus da imunodeficiência humana, o HIV. Entre os diferentes públicos em que a PrEP foi disponibilizada estão jovens de 15 a 24 anos, na tentativa de estimular seu autocuidado e diminuir a incidência de novas infecções no futuro. O objetivo deste trabalho foi analisar a adesão desses jovens à profilaxia e possíveis consequências dessa atitude, por meio de revisão sistemática e metanálise de artigos publicados até a data da busca. Apesar de a maioria dos estudos ter sido realizada em um único país, foi possível identificar uma tendência de aumento nas taxas de adesão à PrEP, especialmente por parte dos homens que fazem sexo com homens de, em média, 20 anos de idade. Com a complexidade da infecção pelo HIV e das novas formas de prevenção, como a PrEP, torna-se necessária a realização de novos estudos a fim de avaliar a adesão de outros grupos populacionais a essas estratégias e o impacto dessa adoção a longo prazo.

DeCS: Prevenção \& controle; Prevenção de doenças; Profilaxia Pré-Exposição. 


\begin{abstract}
Pre-Exposure Prophylaxis - PrEP is a form of drug therapy released in 2012 in the United States to prevent further infections by the human immunodeficiency virus, HIV. Among the different audiences in which PrEP was made available, are young people aged 15-24 years old, in an attempt to stimulate their self-care and decrease the incidence of new infections in the future. The objective of this study was to analyze the adherence of these young people to this prophylaxis and the possible consequences of this attitude, through systematic review and meta-analysis of articles published to the date of search. Although most studies were conducted in a single country, it was possible to identify a trend towards increased rates of adherence to PrEP, especially among men who have sex with men, on average, 20 years old. With the complexity of HIV infection and new forms of prevention, such as PrEP, further studies are needed to assess the adherence of other population groups to these strategies and the long-term impact of their adoption.
\end{abstract}

DeCS: Prevention \& Control; Prevention of diseases; Pre-Exposure Prophylaxis 


\section{LISTA DE FIGURAS E QUADROS}

Figura 1 - Ciclo de vida do HIV no hospedeiro

Figura 2 - Árvore filogenética de SIV e HIV-1

Figura 3 - Diferença do genoma entre HIV-1 e HIV-2

Figura 4 - Ciclo de vida do HIV e principais locais de ação dos fármacos atuantes na terapia antirretroviral (TARV)

Figura 5 - Estratégias de prevenção combinada preconizadas pelo Departamento de Doenças de Condições Crônicas e Infecções Sexualmente Transmissíveis do Ministério da Saúde.

Figura 6 - Cascata de diagnóstico e tratamento para supressão viral de 73\% dos indivíduos infectados até 2020

Figura 7 - Porcentagem de países em relação à adesão à TARV e em relação à taxa de supressão viral

Figura 8 - Fluxograma da busca e seleção dos estudos

Tabela 1 - Fármacos utilizados na terapia antirretroviral (TARV) combinada com seu mecanismo de ação e principais efeitos adversos

Quadro 1 - Diferentes abordagens de prevenção combinada preconizadas pelas Diretrizes Nacionais de Prevenção Combinada em HIV/AIDS

Quadro 2 - Estudos incluídos na revisão 


\section{LISTA DE ABREVIATURAS E SIGLAS}

HIV - Vírus da Imunodeficiência Humana

CD4+- Cluster of Differentiation 4

CCR5 - Receptor de quimiocinas C-C tipo 5

CXCR4 - Receptor de quimiocinas C-X-C tipo 4

AIDS - Síndrome da Imunodeficiência Adquirida

CRFs - Formas recombinantes combinantes

URFs - Formas recombinantes únicas

SIV - Vírus da Imunodeficiência Símia

DSTs - Doenças Sexualmente Transmissíveis

TARV - Terapia Antirretroviral

SUS - Sistema Único de Saúde

ISTs - Infecções sexualmente transmissíveis

PREP - Profilaxia Pré-Exposição

PEP - Profilaxia Pós-Exposição

UNAIDS - Programa Conjunto das Nações Unidas sobre HIV/AIDS

RNA - Ácido ribonucleico

DNA - Ácido desoxirribonucleico

HSH - Homens que fazem sexo com homens

FDA - Food and Drug Administration

CDC - Centers for Disease Control

OMS - Organização Mundial da Saúde

PRISMA - Preferred Reporting Items for Systematic Reviews and Meta-Analyses

PVHA - Pessoas vivendo com HIV/AIDS 
ÍNDICE

RESUMO

4

ABSTRACT

1. INTRODUÇÃO 9

1.1 - ASPECTOS HISTÓRICOS DO HIV 9

1.2 - ASPECTOS GENÉTICOS

1.3 - ASPECTOS EPIDEMIOLÓGICOS

1.4 - ESTRATÉGIAS DE PREVENÇÃO E TRATAMENTO DO HIV/AIDS 12

2. REFERENCIAL TEÓRICO

2.1 - A TERAPIA COMO PREVENÇÃO

2.2 - A META INTERNACIONAL

2.3 - A PREP 16

3. OBJETIVOS 18

3.1 OBJETIVO GERAL $\quad 18$

3.2 OBJETIVOS ESPECÍfICOS

4. METODOLOGIA 19

4.1 SOBRE A BUSCA DE DADOS E INFORMAÇÕES 19

4.2 CRITÉRIOS DE ELEGIBILIDADE DOS ESTUDOS 19

4.3 EXTRAÇÃO DOS DADOS 19

5. RESULTADOS E DISCUSSÃO

6. CONCLUSÃO 28

7. REFERÊNCIAS 29 


\section{INTRODUÇÃO}

\section{1 - ASPECTOS HISTÓRICOS DO HIV}

$\mathrm{O}$ vírus da imunodeficiência humana (HIV) é um lentivírus pertencente à família Retroviridae $^{[1]}$ e descrito pela primeira vez em 1981, quando homens jovens homossexuais começaram a desenvolver doenças de rara malignidade ${ }^{[2]}$, se espalhando rapidamente pelos Estados Unidos, África Central e Oriental, além de vários países europeus e da América Central $^{[3]}$.

Descobriu-se que a infecção aguda pelo HIV cursava com uma síndrome mono-like, com sintomas como rash máculo-papular, febre, mialgia, artralgia, dor de cabeça e diarreia ${ }^{[3]}$ e que, com o tempo, o vírus era atraído para dentro de linfócitos T CD4+ ativados, por afinidade receptores de quimiocinas CCR5 ou CXCR4, infectando e destruindo estas células, assim como utilizando macrófagos e células dendríticas como reservatórios ${ }^{[4]}$. Com o tempo, evidenciou-se que a diminuição do número de linfócitos $\mathrm{T} \mathrm{CD}^{+}{ }^{+}$levava a um quadro de imunodeficiência adquirida, conhecido como $\operatorname{AIDS}^{[1]}$.

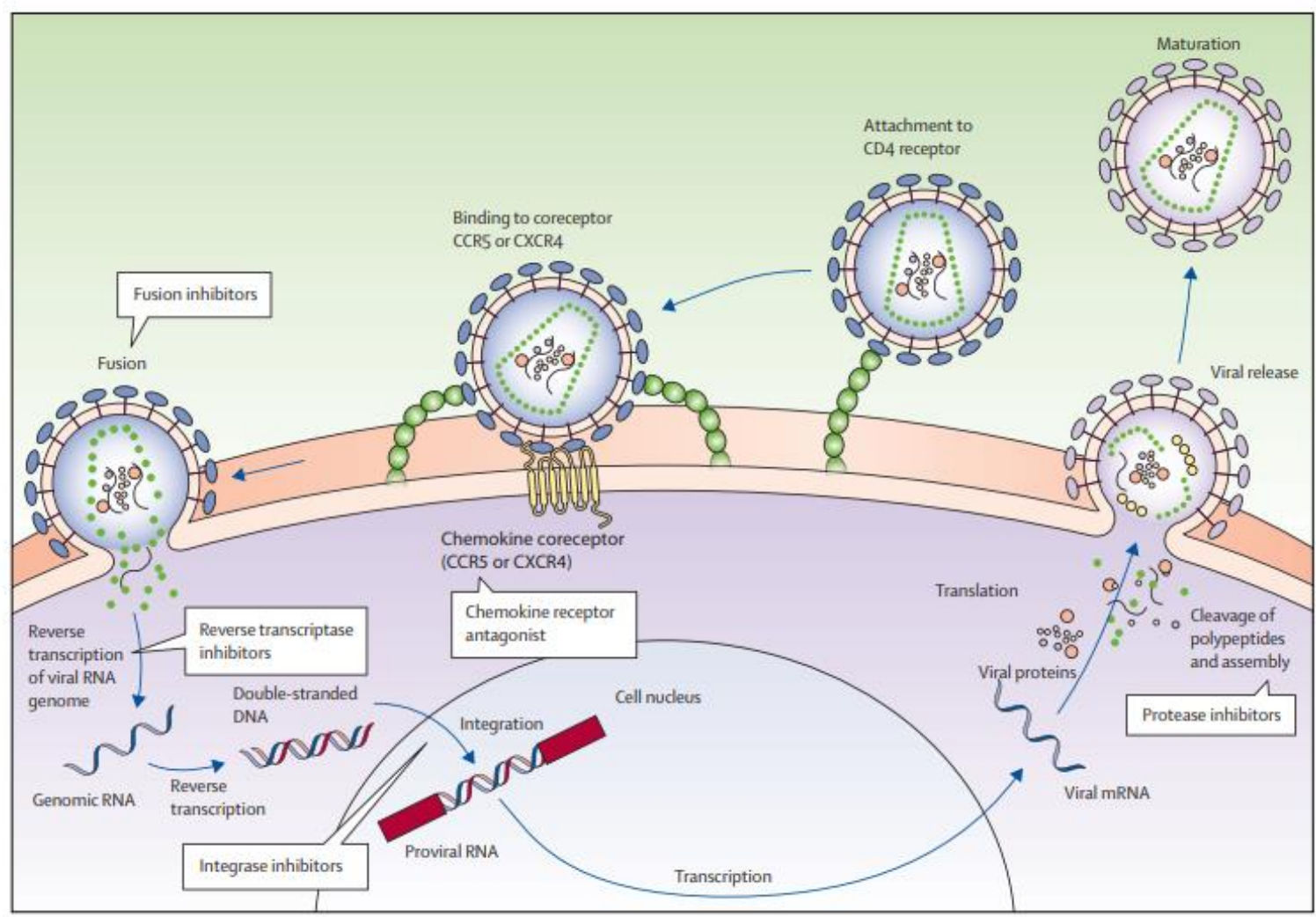

Figura 1 - Ciclo de vida do HIV no hospedeiro. (Fonte: Maartens, 2014) 


\section{2 - ASPECTOS GENÉTICOS}

Ao longo das pesquisas iniciadas nos anos 80, foram identificados dois tipos do vírus da imunodeficiência humana, denominados HIV-1 e HIV-2, existindo, entre eles, subtipos e formas recombinantes circulantes (CRFs) e formas recombinantes únicas (URFs) ${ }^{[5]}$. Hoje, já se reconhece que o vírus HIV que atingiu os humanos no início da epidemia derivou de um vírus de imunodeficiência símia (SIV) dos chimpanzés selvagens no Camarões ${ }^{[6]}$. É possível analisar a relação filogenética de ancestralidade entre as duas espécies de vírus na figura a seguir:

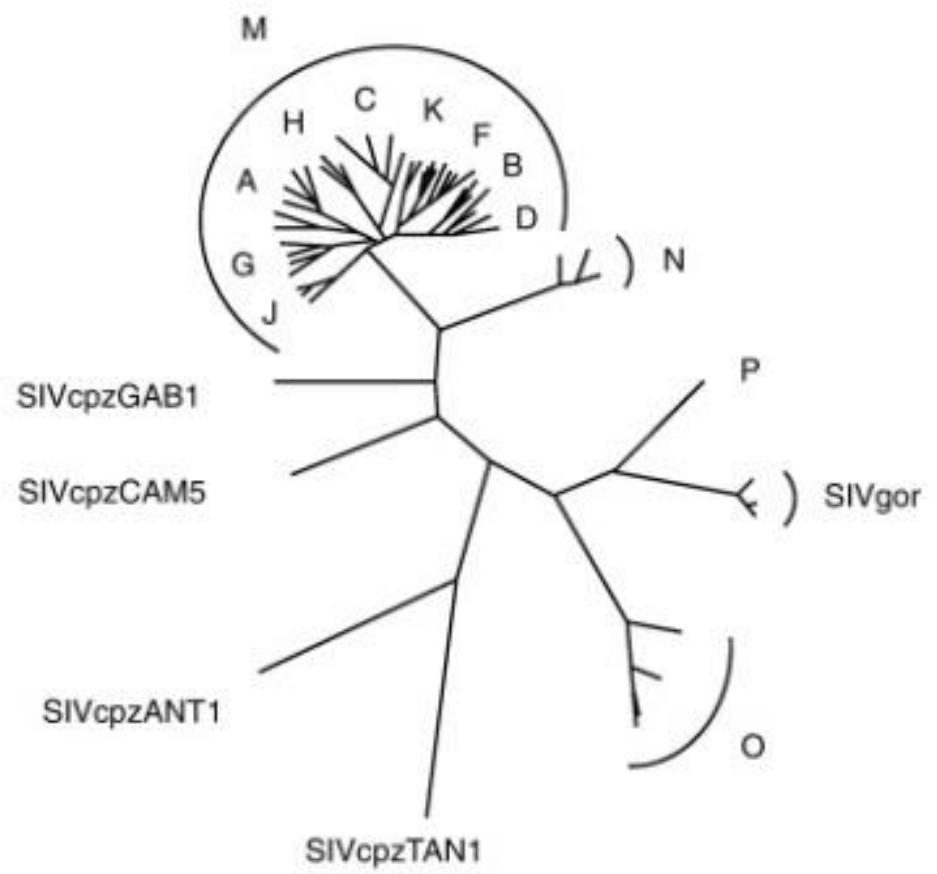

Figura 2 - Árvore filogenética de SIV e HIV-1. (Fonte: Hemelaar, 2012)

A descoberta dessas relações filogenéticas possibilitou, com o passar do tempo, a identificação de nove subtipos do HIV-1 tipo M (representativo de major), sendo eles: A, B, $\mathrm{C}, \mathrm{D}, \mathrm{F}, \mathrm{G}, \mathrm{H}, \mathrm{J}, \mathrm{K}$, juntamente com formas recombinantes (CRFs) do vírus ${ }^{[8]}$. Gremk descreveu, em 1995, o caráter da epidemia em seus primeiros sítios:

A pandemia, que hoje grassa, resulta da sobreposição de, pelo menos, duas epidemias diferentes, provocadas por dois germes distintos: HIV-1 e HIV2. São parentes colaterais, pois as sequências de seus genomas são tais que um não pode ser descendente do outro. A epidemia causada pelo HIV-2 teria, com certeza, passado despercebida se a gravidade da primeira não tivesse aguçado o olho clínico dos médicos e orientado as pesquisas dos virologistas. Essa segunda epidemia esteve, no início, circunscrita a um foco apenas, na África oriental, enquanto a disseminação mundial do HIV1 partiu de três focos identificados: um na África central e outros dois no litoral da América do Norte. Os dois focos-americanos têm origem comum, 
mas não se sabe se, nos dois continentes, os surtos tiveram origens independentes e, de alguma forma, paralelas ou se um provocou o outro.

Tanto o HIV-1 quanto o HIV-2, descritos na literatura científica atual, possuem três genes principais no seu genoma: gag, pol, e env-, responsáveis por codificar as proteínas estruturais e não estruturais comuns à replicação desses retrovírus ${ }^{[10]}$. Após o processo de clivagem pós-traducional, as proteínas virais formadas são: proteínas nucleares p17, p24 e p15 - a partir do gene gag -, as enzimas protease, transcriptase reversa e integrase, traduzidas do gene $p o l-e$ as duas glicoproteínas de envelope gp41 e gp120, derivadas do gene $e n v^{[11]}$.

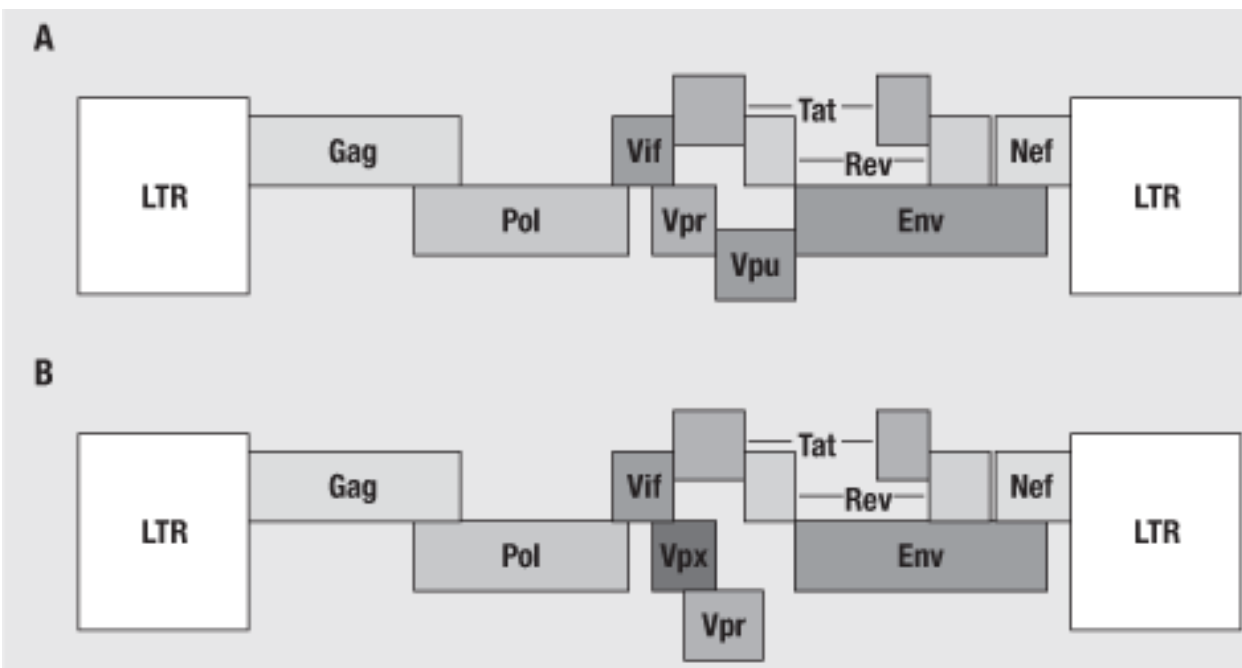

Figura 3 - Diferença do genoma entre HIV-1 e HIV-2. (Fonte: Fanales-Belasio, 2010)

Apesar das semelhanças estruturais genéticas, o HIV-1 difere do tipo 2 devido a uma mudança no locus gênico desses genes princiapais, conforme representado na Figura 3. Esse fator promove diferenças antigênicas e imunogênicas entre os vírus. O HIV-2 é caracterizado por uma menor probabilidade de desenvolvimento do quadro de $\operatorname{AIDS}^{[13]}$, chegando a imunodeficiência a ser desenvolvida somente em 20 a $30 \%$ das pessoas que vivem com HIV$2^{[14]}$. Além disso, foram relatadas taxas reduzidas de transmissão do vírus entre heterossexuais e baixas taxas de desenvolvimento de outras doenças ${ }^{[15]}$.

\section{3 - ASPECTOS EPIDEMIOLÓGICOS}

De acordo com o Ministério da Saúde, o primeiro caso de AIDS no Brasil foi identificado na cidade de São Paulo no ano de 1980 e os casos posteriores ficaram restritos às metrópoles nacionais ${ }^{[16]}$; por fim, se disseminaram para as demais regiões nacionais ${ }^{[17]}$. 
Apesar do grupo de homens homossexuais ser historicamente o primeiro acometido pela infecção ${ }^{[18]}$, a epidemia da AIDS tem passado por uma mudança de público, acometendo mais pessoas heterossexuais, pobres, do sexo feminino, de moradia no interior e jovens ${ }^{[19]}$, perfil social muito semelhante ao identificado num estudo comparativo entre França e Brasil $^{[20]}$.

Segundo o mesmo estudo comparativo, o número de jovens brasileiros vivendo com HIV é 3,5 vezes maior que o mesmo público na França, país que adota políticas de educação sexual já nas escolas e a notificação da AIDS e HIV são obrigatórias às autoridades de saúde do país. Esse crescimento das taxas de infecção por HIV e AIDS nos jovens do país ao longo dos anos é evidenciado pelo próprio Ministério da Saúde do Brasil. Segundo o Boletim Epidemiológico de AIDS e DSTs de 2012, até o final do respectivo ano, haviam sido registrados 109.243 casos em faixa etária de 10 a 24 anos, correspondendo a 16,6\% da população total que vive com o vírus no país.

Entre as principais dificuldades encontradas no enfrentamento da AIDS nesse público identificado, vale destacar como principal fator de transmissão do vírus a prática sexual sem preservativo ou o uso apenas ocasional deste, seja com parceiro fixo ou eventual $^{[22]}$, apesar das diversas campanhas de saúde pública que conferiram internacionalmente ao Brasil o título de referência mundial no combate e tratamento da $\operatorname{AIDS}^{[23]}$.

\section{4 - ESTRATÉGIAS DE PREVENÇÃO E TRATAMENTO DO HIV/AIDS}

A partir da vigência da Lei Federal no 9.313/96, a terapia antirretroviral (TARV) começou a ser distribuída gratuitamente pelo Sistema Único de Saúde (SUS) em todo o território nacional, permitindo às pessoas que viviam com HIV e AIDS viverem por mais tempo ${ }^{[24]}$. Essa lei visava também a diminuição de gastos do governo a partir da redução do número de internações hospitalares por AIDS, como atendimento ambulatorial especializado, acompanhamento domiciliar terapêutico e acesso a hospitais-dia ${ }^{[25]}$. 
A manutenção da gratuidade e universalidade da Terapia Anti-Retroviral (TARV) até os dias de hoje permanece apoiada em dois pilares principais: a redução do número de mortes por HIV/AIDS e a redução dos custos das internações hospitalares e infecções oportunistas $^{[26]}$. Atualmente, os fármacos utilizados na TARV são:

Tabela 1 - Fármacos atualmente utilizados na terapia antirretroviral (TARV) combinada com seu mecanismo de ação e principais efeitos adversos

\begin{tabular}{|c|c|c|c|}
\hline Classe & Nome genérico & Mecanismo de açăo & Efeitos adversos \\
\hline $\begin{array}{l}\text { Inibidores da Transcriptase Reversa } \\
\text { Análagos de Nucleosídeos (ITRN) }\end{array}$ & $\begin{array}{l}\text { Abacavir (ABC), Didanosina (ddl), } \\
\text { Estavudina (d4T), Lamivudina (3TC), } \\
\text { Zidovudina (AZT) Tenofovir (TDF)* }\end{array}$ & \multirow{2}{*}{$\begin{array}{l}\text { Impedem a infecçăo aguda das } \\
\text { células, pois atuam sobre a } \\
\text { transcriptase reversa, impedindo que } \\
\text { o RNA viral se transforme em DNA } \\
\text { complementar }\end{array}$} & $\begin{array}{l}\text { toxicidade mitocondrial; toxicidade } \\
\text { hepática, lipoatrofia, anemia, miopatia, } \\
\text { neuropatia periférica, pancreatite }\end{array}$ \\
\hline $\begin{array}{l}\text { Inibidores da Transcriptase Reversa } \\
\text { Năo-Análagos de Nucleosideos } \\
\text { (ITRNN) }\end{array}$ & $\begin{array}{l}\text { Efavirenz (EFZ), Nevirapina (NVP), } \\
\text { delavirdina }\end{array}$ & & $\begin{array}{l}\text { Elevação das enzimas hepáticas, } \\
\text { dislipidemia, exantema e sindrome de } \\
\text { Stevens-Johnson. }\end{array}$ \\
\hline Inibidores de Protease (IP) & $\begin{array}{c}\text { Fosamprenavir (FAPV), Atazanavir } \\
\text { (ATV), Darunavir (DRV), Indinavir } \\
\text { (IDV), Lopinavir (LPV), Nelfinavir } \\
\text { (NFV), Ritonavir (RTV), Saquinavir } \\
\text { (SQV) }\end{array}$ & $\begin{array}{l}\text { Atuam impedindo a clivagem da } \\
\text { protease do polipeptideo precursor } \\
\text { viral e bloqueia a maturaçăo do vírus }\end{array}$ & $\begin{array}{l}\text { Toxicidade metabólica; lipodistrofia, } \\
\text { dislipidemia, hiperglicemia, resistência } \\
\text { a insulina, diabetes, intoleråncia } \\
\text { gastrointestinal, toxicidade hepática }\end{array}$ \\
\hline $\begin{array}{l}\text { Inibidores da entrada do HIV } \\
\text { Inibidor da fusăo }\end{array}$ & Enfuvirtida (T-20) & $\begin{array}{l}\text { Impedem a entrada do material } \\
\text { genético viral pela sua açăo no } \\
\text { mesmo local da entrada do HIV na } \\
\text { célula que expressa receptor CD4 }\end{array}$ & $\begin{array}{c}\text { Reaçōes de } \\
\text { Hipersensibilidade, principalmente } \\
\text { local, ou, mais raramente } \\
\text { sistêmica }\end{array}$ \\
\hline
\end{tabular}

"análogo de nucleotideo.

Tabela 1 - Fármacos utilizados na terapia antirretroviral (TARV) combinada com seu mecanismo de ação e principais efeitos adversos. (Fonte: Kramer, 2009).

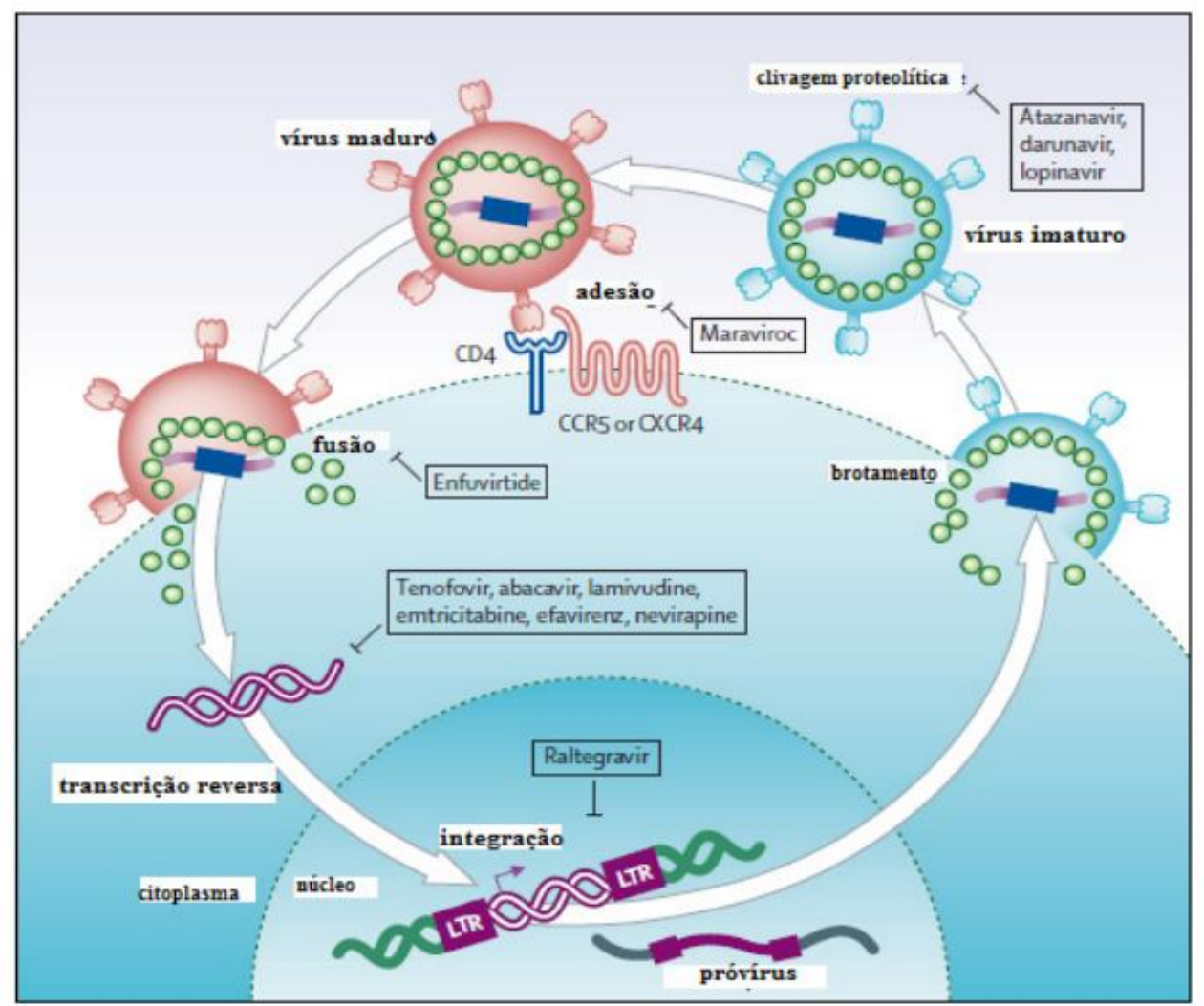

Figura 4 - Ciclo de vida do HIV e principais locais de ação dos fármacos atuantes na terapia antirretroviral (TARV); (Fonte: Silveira, 2011). 
Atualmente, o método profilático mais comumente utilizado é o preservativo, método eficaz não apenas para prevenção de HIV, mas para outras infecções sexualmente transmissíveis - ISTs - como sífilis, clamídia, gonorreia, entre outras ${ }^{[29]}$, estando disponível na rede pública de saúde desde 1996, pela mesma lei dos antirretrovirais. Porém, ainda de acordo com o Ministério da Saúde, o grupo etário de 15 a 19 anos apresenta os menores índices de uso de preservativo ${ }^{[30]}$, favorecendo as taxas de infecção entre adolescentes e prevalência de AIDS em jovens ${ }^{[22]}$.

Diante do exposto, torna-se imprescindível analisar os estudos até hoje realizados sobre a adesão dos jovens às novas formas de terapia combinada como a PrEP, a fim de avaliar a efetividade da Profilaxia nesse público e suas implicações no organismo dessas pessoas e nas taxas da infecção ao redor do mundo.

\section{REFERECIAL TEÓRICO}

\section{1 - A TERAPIA COMO PREVENÇÃO}

Além das entidades internacionais, a Sociedade Brasileira de Infectologia, num ofício enviado ao Ministro da Saúde em 28 de novembro de 2018 com o tema "Programa de Prevenção e Tratamento de HIV/AIDS", reconhece que as políticas de prevenção à transmissão do HIV devem contemplar as estratégias combinadas.

As estratégias combinadas, além das técnicas anteriormente citadas, incluem outras práticas como:

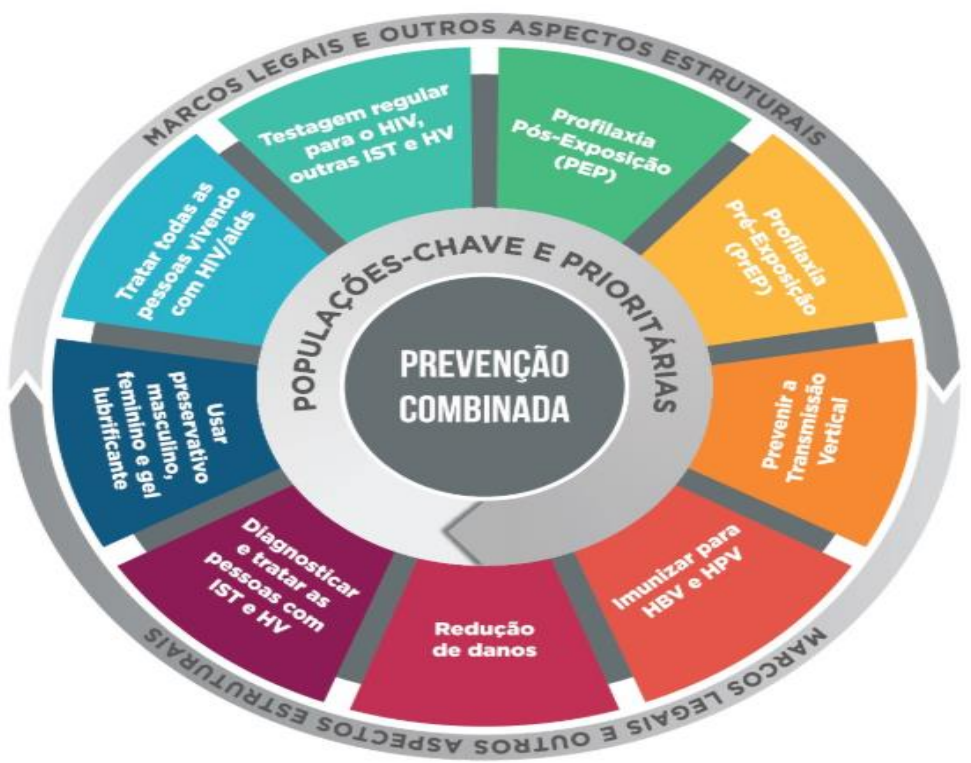

Figura 5 - Estratégias de prevenção combinada preconizadas pelo Departamento de Doenças de Condições Crônicas e Infecções Sexualmente Transmissíveis do Ministério da Saúde. Fonte: < http://www.aids.gov.br/pt-br/publico-geral/previna-se>. Acesso em: 26 de julho de 2018. 
O Ministério da Saúde traz, nas Diretrizes Nacionais de Prevenção Combinada em HIV/AIDS, a seguinte definição:

Prevenção Combinada é uma estratégia que faz uso simultâneo de diferentes abordagens de prevenção (biomédica, comportamental e socioestrutural) aplicadas em múltiplos níveis (individual, nas parcerias/relacionamentos, comunitário, social) para responder a necessidades específicas de determinados públicos e de determinadas formas de transmissão do HIV.

Nesse sentido, estão diferenciados três tipos de intervenção na prevenção combinada: as intervenções biomédicas, as comportamentais e as estruturais.

\begin{tabular}{|c|c|c|}
\hline Tipo de intervenção & Ação & Exemplo \\
\hline $\begin{array}{l}\text { Intervenções } \\
\text { biomédicas }\end{array}$ & $\begin{array}{c}\text { Voltadas ao risco de } \\
\text { exposição, intervindo entre o } \\
\text { HIV e a pessoa passível de } \\
\text { infecção }\end{array}$ & $\begin{array}{c}\text { TARV, PrEP, PEP, } \\
\text { preservativos e lubrificantes }\end{array}$ \\
\hline $\begin{array}{c}\text { Intervenções } \\
\text { comportamentais }\end{array}$ & $\begin{array}{l}\text { Estimulam uma mudança de } \\
\text { comportamento no indivíduo, } \\
\text { chamando atenção para os } \\
\text { riscos de infecção e medidas } \\
\text { de proteção }\end{array}$ & $\begin{array}{c}\text { Incentivo ao uso de } \\
\text { preservativos e lubrificantes, } \\
\text { incentivo à testagem, } \\
\text { vinculação aos serviços de } \\
\text { saúde }\end{array}$ \\
\hline $\begin{array}{l}\text { Intervenções } \\
\text { estruturais }\end{array}$ & $\begin{array}{l}\text { Voltadas às condições } \\
\text { socioculturais e de } \\
\text { vulnerabilidade de grupos } \\
\text { mais suscetíveis ao HIV, } \\
\text { defendendo a dignidade } \\
\text { humana }\end{array}$ & $\begin{array}{l}\text { Campanhas educativas à } \\
\text { população, profissionais de } \\
\text { saúde, combate às } \\
\text { discriminações }\end{array}$ \\
\hline
\end{tabular}

\section{2 - A META INTERNACIONAL}

A partir do ano de 2015, o Programa Conjunto das Nações Unidas sobre HIV/AIDS (UNAIDS) iniciou uma discussão em plano global, traçando metas para erradicação do HIV/AIDS até 2020 ${ }^{[31]}$. Essas metas, tidas por alcançáveis, incluíam uma cascata de tratamento que tem por objetivo final o alcance da meta denominada "três noventas":

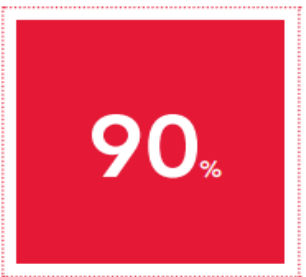

diagnosticados

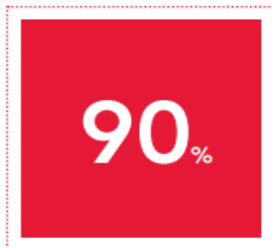

em tratamento

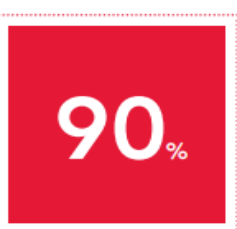

com supressão viral

Figura 6 - Cascata de diagnóstico e tratamento para supressão viral de 73\% dos indivíduos infectados até 2020. Fonte: (UNAIDS, 2015). 
Em termos práticos, as metas estabelecidas pela UNAIDS compreendiam que até 2020: $90 \%$ de todas as pessoas com HIV saberão que tem o vírus; $90 \%$ de todos os diagnosticados com HIV estarão recebendo TARV ininterrupta; $90 \%$ das pessoas em TARV estarão em supressão viral, ou em outras palavras, terão carga viral indetectável ${ }^{[31]}$. Porém, alguns estudos como Levi (2016), demonstram que até o momento do estudo, nenhum país havia conseguido alcançar as metas 90-90-90.

A

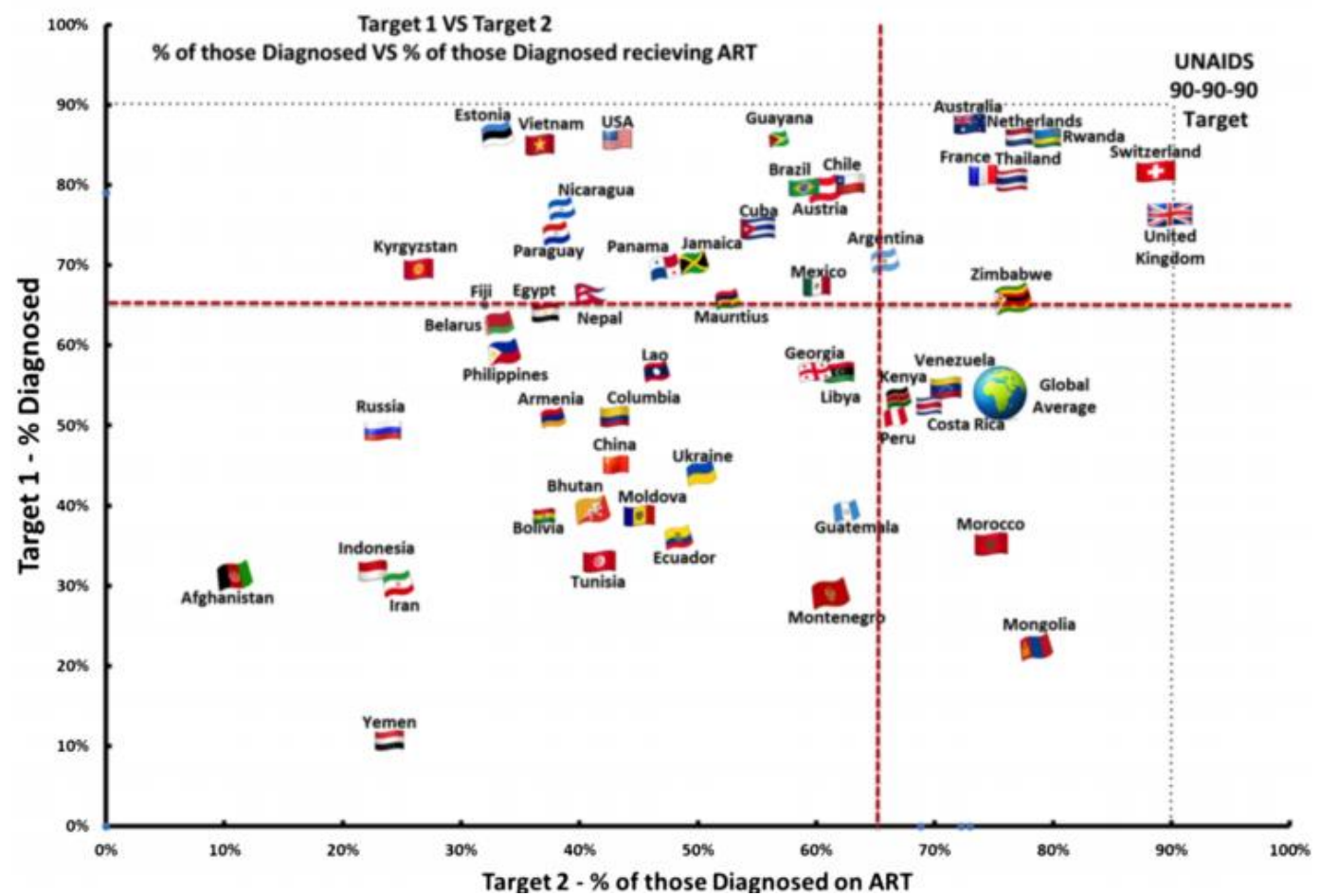

Figura 7 - Porcentagem de países em relação à adesão à TARV e em relação à taxa de supressão viral. Fonte: (LEVI, 2016).

\section{3 - A PrEP}

Diante dos quadros mundiais de HIV, foi aprovada no ano de 2012 nos Estados Unidos uma nova modalidade de terapia medicamentosa de prevenção ao HIV denominada Profilaxia Pré-Exposição (PrEP), uma nova classe de fármacos encontrada em duas formas, sendo a primeira delas e mais comum a forma oral - um combinado dos antirretrovirais Tenofovir e Emtricitabina, comercializada com o nome de Truvada ${ }^{\circledR}$ - e a forma tópica, menos comum, contendo apenas Tenofovir ${ }^{[33]}$. Esses fármacos pertencem à classe dos inibidores da transcriptase reversa, sendo fosforilados no interior da célula nos anabólitos difosfato (DP) e trifosfato (TP), moléculas farmacologicamente ativas ${ }^{[34]}$ que atuam como inibidores competitivos ou substrato alternativo da enzima transcriptase reversa ${ }^{[35]}$, capazes de impedir a conversão da dupla fita de RNA em pró-DNA viral no interior das células do 
hospedeiro $^{[36]}$, bloqueando a replicação do vírus, a disseminação da infecção e a evolução para um quadro de imunodeficiência, conforme o esquema disponível na Figura 4.

Essa modalidade de terapia foi aprovada, a priori, para uso em três grupos: homens que fazem sexo com homens (HSH), casais sorodiscordantes e indivíduos com alto risco de infecção - como profissionais do sexo. Após alguns testes, a PrEP foi aprovada para uso mundial em 2012 por alguns órgãos de saúde internacionais, como a Food and Drug Administration (FDA), Center of Diseases Control (CDC) e a Organização Mundial de Saúde (OMS) ${ }^{[37]}$. No ano de 2015, a UNAIDS, juntamente com a OMS publicaram o documento Oral Pre-Exposure Prophylaxis: putting a new choice in context, ressaltando todas as evidências científicas de funcionamento da PrEP, assim como destacando o alto grau de adesão à nova forma de prevenção e as baixas reações adversas decorrentes do uso contínuo da mesma ${ }^{[38]}$.

No Brasil, o Ministério da Saúde, por meio do Departamento de DST, AIDS e Hepatites Virais anunciou em 2013 uma mudança no protocolo da TARV, passando essa a ser administrada em todos os indivíduos vivendo com HIV, independentemente da sua carga viral. Nesse mesmo pronunciamento, o Ministério da Saúde implantou um projeto-piloto da PrEP no país para pessoas soronegativas, porém consideradas grupos de risco - HSH, travestis, transexuais, profissionais do sexo e usuários de drogas injetáveis ${ }^{[39]}$. Essas restrições estariam baseadas em estudos que mostram uma relação inversamente proporcional para o indivíduo em relação ao benefício. Ou seja: indivíduos de baixo risco estariam mais expostos a riscos desnecessários do que se estivessem utilizando os métodos profiláticos convencionais, como os preservativos ${ }^{[40]}$.

Hoje, no Sistema Único de Saúde (SUS), a PrEP é distribuída em trinta e seis unidades distribuídas em vinte e duas cidades brasileiras, um número ainda aquém da demanda do público alvo. Segundo o Departamento de Doenças de Condições Crônicas e Infecções Sexualmente Transmissíveis do Ministério da Saúde, desde 18 de dezembro de 2017, 10 estados e o Distrito Federal distribuem a PrEP a partir de unidades que participaram do projeto-piloto de 2013. Na Bahia, o protocolo de distribuição da PrEP se encontra disponível em seis unidades de aconselhamento e assistência, alocadas em quatro municípios do estado, sendo eles: Itabuna, Porto Seguro, Salvador e Vitória da Conquista. 


\section{OBJETIVO}

\subsection{OBJETIVO GERAL}

Avaliar a adesão e os efeitos da Profilaxia Pré-Exposição (PrEP) entre os adolescentes e jovens em diferentes países através de uma revisão sistemática.

\subsection{OBJETIVOS ESPECÍFICOS}

- Analisar a faixa etária mais prevalente dos jovens em uso de PrEP atualmente no mundo;

- Avaliar o grupo populacional entre os jovens que possui a maior adesão à profilaxia; 


\section{4 - METODOLOGIA}

O presente estudo se trata de uma revisão sistemática de literatura desenvolvida de acordo com as recomendações PRISMA (Preferred Reporting Items for Systematic Reviews and Meta-Analyses) e de forma descritiva, buscando analisar qualitativamente e quantitativamente a adesão de jovens ao redor do mundo à Profilaxia Pré-Exposição (PrEP).

\section{1 - SOBRE A BUSCA DE DADOS E INFORMAÇÕES}

Os artigos selecionados para o estudo foram obtidos a partir das bases de dados Pubmed (https://www.ncbi.nlm.nih.gov/pubmed/),

ScienceDirect (https://www.sciencedirect.com/), Scielo (http://www.scielo.br/cgibin/wxis.exe/iah/?IsisScript=iah/iah.xis\&base=article\%5Edlibrary\&fmt=iso.pft\&lang=p) e LILACS (http://lilacs.bvsalud.org/).

Para a presente revisão, foram selecionados estudos publicados até os dias atuais, a partir das palavras-chaves: "PrEP adherence" ou "PrEP young". Para a base de dados ScienceDirect foi possível utilizar o operador booleano AND, concatenando as palavraschaves "PrEP AND young AND adherence".

\section{2 - CRITÉRIOS DE ELEGIBILIDADE DOS ESTUDOS}

Foram incluídos na análise todos os estudos descritivos (transversal, coorte e ensaio clínico), publicados nas bases de dados reportadas num período de 2012 a 2019, período que compreende desde a criação e aprovação do uso da PrEP até os dias atuais.

\section{3 - EXTRAÇÃO DE DADOS}

Após as buscas nas bases de dados, a seleção dos artigos foi iniciada com a leitura dos títulos e resumos dos mesmos, seguindo os critérios de elegibilidade nas seguintes etapas: (i) eliminação das duplicatas; (ii) eliminação das publicações anteriores ao ano de 2012; (iii) publicações fora do tema de PrEP e/ou público jovem; (iv) análise de texto inteiro dos 22 estudos restantes para inclusão na revisão; 
Foi criada uma planilha eletrônica no Excel 2016 a fim de orientar a análise das vinte e duas publicações restantes. Foram elencadas as seguintes categorias para preenchimento após leitura dos textos completos: (i) autor da publicação; (ii) ano da publicação; (iii) local do estudo; (iv) ano(s) de realização do estudo; (v) local do estudo; (vi) número de participantes; (vii) público envolvido com a pesquisa; (viii) média de idade dos envolvidos; (ix) taxa de adesão à PrEP; (x) desenvolvimento de ISTs após o uso da profilaxia, se reportado; (xi) IST mais prevalente no estudo, se reportada.

Após a etapa de leitura integral e tabulação dos dados presentes nos estudos, foram incluídas 14 (catorze) publicações na análise final desse estudo. O fluxograma de análise dos dados segue na Figura 8.

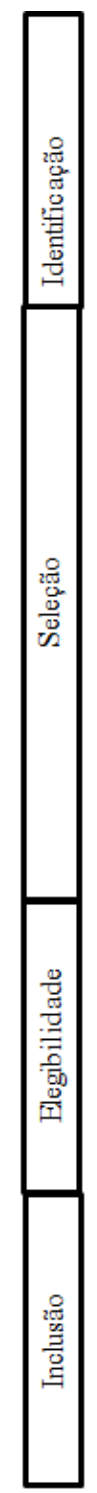

2.733 publicações identificadas nas bases de dados:

1.420 - PubMed

06 - Scielo

1.283 - Science Direct

04 - LILACS

22 publicações repetidas eliminadas

2.711 publicações rastreadas

882 publicações anteriores ao ano de 2012 eliminadas

1.829 publicações selecionadas

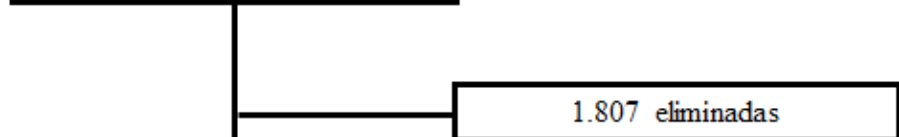

22 publicações em texto completo avaliadas para eligibilidade

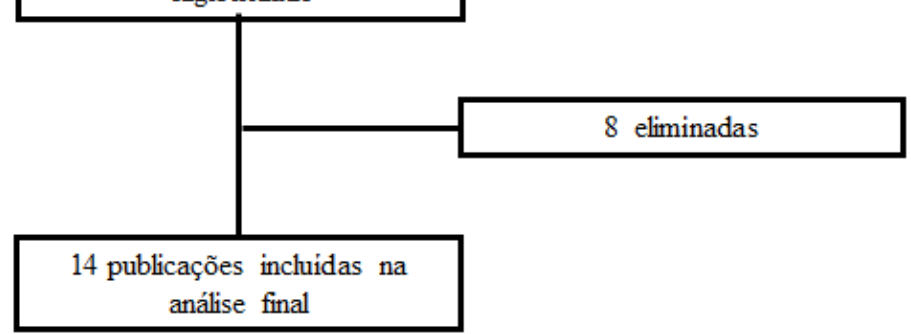

Figura 8 - Fluxograma da busca e seleção dos estudos (elaborado pelo autor). 


\section{5 - RESULTADOS E DISCUSSÃO}

Foram identificados 2.733 estudos nas quatro bases de dados pesquisadas, dos quais 14 deles foram incluídos na análise final; suas características e resultados se encontram disponíveis no Quadro 2. Foi possível identificar um pico de publicações sobre o tema no ano de 2017, concentrando 5 dos 14 trabalhos incluídos. Desses, 13 foram realizados no território dos Estados Unidos e somente 1 na Tailândia.

Os estudos incluídos na revisão foram tabulados, a fim de analisar os seguintes critérios: (i) ano de publicação; (ii) tipo de estudo; (iii) ano(s) do estudo; (iv) local do estudo; (v) $\mathrm{n}^{\mathrm{o}}$ de participantes; (vi) público; (vii) média de idade; (viii) taxa de adesão; (ix) desenvolvimento de ISTs; (x) IST mais prevalente. 


\begin{tabular}{|c|c|c|c|c|c|c|c|c|c|c|}
\hline Autor & $\begin{array}{c}\text { Ano de } \\
\text { publicação }\end{array}$ & Tipo de estudo & Ano(s) do estudo & Local do estudo & $\begin{array}{c}\text { № de } \\
\text { participantes }\end{array}$ & Público & Média de idade & $\begin{array}{c}\text { Taxa de adesão } \\
\text { (n ou \%) }\end{array}$ & $\begin{array}{c}\text { Desenvolvimento } \\
\text { de ISTs? }\end{array}$ & $\begin{array}{c}\text { IST mais } \\
\text { prevalente }\end{array}$ \\
\hline Wood & 2017 & Transversal & \begin{tabular}{|c}
$\begin{array}{c}\text { Fevereiro a dezembro } \\
\text { de } 2015\end{array}$ \\
\end{tabular} & Filadélfia & 25 & Mulheres trans jovens & $21.2(17-24)$ & $28 \%(n=7)$ & Não relatado & - \\
\hline Hosek & 2013 & $\begin{array}{l}\text { Ensaio clínico } \\
\text { randomizado }\end{array}$ & - & Chicago & $\begin{array}{c}68 \\
\text { (20 receberam PrEP) }\end{array}$ & HSH jovens & $19.97(18-22)$ & $84,6 \%(n=36)$ & $\operatorname{sim}$ & Clamídia (n=7) \\
\hline Desrosiers & 2018 & $\begin{array}{l}\text { Ensaio clínico } \\
\text { randomizado }\end{array}$ & $\begin{array}{l}\text { Agosto de } 2016 \text { a } \\
\text { fevereiro de } 2017\end{array}$ & Washington & $\begin{array}{c}60 \\
\text { (25 receberam PrEP) }\end{array}$ & HSH negros jovens & $21.7(16-25)$ & $8,3 \%(n=4)$ & $\operatorname{sim}$ & Clamídia $(50 \%, n=15)$ \\
\hline Hosek & 2017 & Coorte & $\begin{array}{l}\text { Agosto de } 2013 \text { a } \\
\text { setembro de } 2014\end{array}$ & EUA (6 cidades) & 72 & HSH jovens & $16.5(15-17)$ & $64 \%(n=46)$ & Sim & Clamídia $(11,1 \%, n=8)$ \\
\hline Seekaew & 2019 & Coorte & $\begin{array}{l}\text { Janeiro de } 2016 \text { a } \\
\text { fevereiro de } 2017\end{array}$ & Tailândia & 653 & HSH e mulheres trans & 28.9 & $62,6 \%(n=409)$ & Não relatado & - \\
\hline Baker & 2017 & Coorte & $\begin{array}{c}\text { Jul ho de } 2013 \text { a jul ho } \\
\text { de } 2015\end{array}$ & EUA (12 cidades) & 167 & HSH jovens & $20(16-23)$ & $38,8 \%(n=65)$ & Não relatado & - \\
\hline Kuhns & 2017 & Coorte & \begin{tabular}{|c|} 
Dezembro de 2014 a \\
Janeiro de 2016
\end{tabular} & $\begin{array}{l}\text { EUA (Chicago e } \\
\text { Houston) }\end{array}$ & 394 & HSH jovens & $24(22-26)$ & $77,1 \%(n=37)$ & Não relatado & - \\
\hline Arrington-Sanders & 2016 & Transversal & $\begin{array}{c}\text { Novembro de } 2014 \text { a } \\
\text { março de } 2015\end{array}$ & EUA & 147 & HSH jovens negros & $21.3(15-24)$ & $8 \%(n=12)$ & Não relatado & - \\
\hline Wood & 2019 & Coorte & - & Filadélfia & 31 & $\begin{array}{c}\text { HSH jovens e } \\
\text { mulheres trans "de } \\
\text { cor" jovens }\end{array}$ & $22(15-24)$ & $48 \%(n=15)$ & Não relatado & - \\
\hline Holloway & 2016 & Transversal & $\begin{array}{c}\text { Julho a agosto de } \\
2015\end{array}$ & Califórnia & 761 & HSH jovens & $23(18-29)$ & $7 \%(n=53)$ & Não relatado & - \\
\hline Kuhns & 2015 & Coorte & $\begin{array}{l}\text { Março de } 2012 \text { a } \\
\text { outubro de } 2014\end{array}$ & $\begin{array}{c}\text { EUA (Chicago, Illinois } \\
\text { e Boston) }\end{array}$ & 180 & Mulheres trans jovens & $23.4(18-29)$ & $26,1 \%(n=47)$ & Não relatado & - \\
\hline Morgan & 2018 & Coorte & 2015 a 2017 & Chicago & 472 & $\begin{array}{c}\text { HSHs e mulheres trans } \\
\text { jovens }\end{array}$ & $20.8(16-29)$ & $21,3 \%(n=100)$ & Não relatado & - \\
\hline Koss & 2017 & Coorte & - & EUA & 243 & HSH jovens & 19 (15-22) & $30 \%(n=73)$ & Não relatado & - \\
\hline Daughtridge & 2014 & Coorte & $\begin{array}{c}\text { Fevereiro a setembro } \\
\text { de } 2013\end{array}$ & Filadélfia & 23 & & $21(17-26)$ & $8,7 \%(n=2)$ & Sim & $\begin{array}{l}\text { Clamídia }(n=3) \text { e } \\
\text { gonorreia }(n=1)\end{array}$ \\
\hline
\end{tabular}

Quadro 2 - Estudos incluídos na revisão. Fonte: Elaborado pelo autor. 
Wood, et al. (2017) realizou um estudo transversal entre fevereiro e dezembro de 2015 na Filadélfia, incluindo vinte e cinco participantes identificadas como mulheres transexuais jovens, de 17 a 24 anos de idade, multirraciais e com status de HIV-negativo ou desconhecido em $68 \%$ das envolvidas. $28 \%$ da amostra relatou fazer uso da profilaxia, evidenciando como barreira principal à adesão a falta de disseminação de informações do tratamento entre as mulheres transexuais, principalmente por parte dos envolvidos no sistema de saúde.

Hosek, et al. (2013) conduziu um ensaio clínico randomizado em duas clínicas de intervenção ao HIV/AIDS na cidade de Chicago. Os participantes eram sessenta e oito HSH com idades entre 18 e 22 anos, maioria de etnia afro-americana, dos quais 20 receberam a PrEP diariamente e o restante recebeu placebo diário. Como resultado, 36 participantes apresentaram comportamento de adesão diária e satisfatória ao tratamento, equivalendo a cerca de $85 \%$ da amostra. Além desse resultado, o estudo identificou 7 casos de clamídia entre os participantes, seguido de 4 casos de sífilis após início do teste.

Desrosiers, et al. (2017) recrutou $50 \mathrm{HSH}$ de 16 a 25 anos de idade para um ensaio clínico realizado na cidade de Washington através de redes sociais e aplicativos de relacionamento. Entre os envolvidos, apenas 4 participantes relataram fazer uso contínuo da PrEP, enquanto 6 deles alegaram ter feito uso do medicamento em algum ponto dos últimos três meses do estudo. 22 participantes tiveram ISTs diagnosticadas durante o desenrolar da pesquisa, sendo a clamídia a infecção mais prevalente, correspondendo a 50\% dos casos diagnosticados.

Hosek, et al. (2017) realizou um estudo de coorte entre agosto de 2013 e setembro de 2014 - em seis cidades dos Estados Unidos - com HSH de idades entre 15 e 17 anos. 72 participantes iniciaram o tratamento com PrEP ao longo das 48 semanas de estudo. Destes, 46 apresentaram adesão à profilaxia durante todo o tempo de condução do estudo, equivalendo a $64 \%$ da amostra. Nesse estudo também foi relatada a ocorrência de ISTs entre os participantes, sendo a clamídia a mais prevalente (8 casos), seguida de seis casos de gonorreia reportados.

Seekaew, et al. (2019) também realizou um estudo de coorte, no período de janeiro de 2016 a fevereiro de 2017 na Tailândia. Participaram, no total, 653 pessoas divididas em dois grupos: HSH e mulheres trans. A média de idade dos participantes foi de 28.9 anos. 409 participantes - equivalente a $62,6 \%$ da amostra - apresentaram boa adesão ao tratamento, com ingesta de 4 ou mais pílulas por semana. O autor não relatou a ocorrência de ISTs entre os participantes. 
Uma coorte realizada por Baker, et al. (2017) entre os meses de julho de 2013 e julho de 2015 em 12 cidades dos Estados Unidos contou com a participação de 167 HSH jovens, com idades entre 16 e 23 anos. A adesão foi mensurada por meio de testes de gota de sangue e preenchimento de questionários semanais. Ao final de vinte e quatro semanas de acompanhamento, somente $38,8 \%$ dos participantes havia tido adesão considerada suficiente à profilaxia, correspondendo a pelo menos 4 comprimidos por semana. Não foram relatas ISTs ao longo do período de acompanhamento entre os participantes.

Entre os meses de dezembro de 2014 e janeiro de 2016 Kuhns, et al. (2017) promoveu um estudo de coorte em duas cidades dos Estados Unidos com $394 \mathrm{HSH}$ participantes e média de idade de 24 anos. Entre esses, somente 48 reportaram já ter feito uso de PrEP. Nessa amostra, 37 envolvidos reportaram ainda fazer uso de PrEP, equivalendo a 77,1\% do público avaliado. Não foram relatadas ISTs durante a condução do estudo ou ao final deste.

Arrington-Sanders, et al. (2016) realizou um estudo transversal entre os meses de novembro de 2014 e março de 2015 nos Estados Unidos. Participaram 147 HSH negros, com média de 21.3 anos de idade. A maioria dos participantes relatou desejo de iniciar a profilaxia, enquanto somente $8 \%$ deles alegou fazer uso da mesma. Entre as dificuldades encontradas à adesão ou uso do medicamento estava um baixo acesso a serviços de saúde, conforme relatado em alguns estudos, experiências negativas prévias ou medo de homofobia ou estigmatização em relação à sexualidade.

Wood, et al. (2019) realizou um estudo de coorte entre 28 HSH e 3 mulheres transexuais negras, com idades entre 15 e 24 anos, considerando uma boa adesão à profilaxia aquelas com níveis consistentes do medicamento na urina e uma retirada semanal de pílulas na farmácia equivalente a 4 ou mais doses por semana. Entre os envolvidos, $48 \%$ deles demonstrou um nível ótimo de adesão à PrEP no momento inicial e continuado da pesquisa. Não foram relatados diagnósticos de ISTs no decorrer do estudo.

Holloway, et al. (2016) conduziu um estudo transversal entre os meses de julho e agosto de 2015. Na pesquisa, foram utilizados questionários online com HSH jovens que utilizavam aplicativos de socialização por GPS. Dos 3.868 usuários que responderam ao questionário, 1.777 se encaixavam no perfil da pesquisa e a amostra final contou com 761 participantes com média de idade de 23 anos. Dentre esses, 53 apresentaram adesão ótima à PrEP, com uso de 6 a 7 vezes por semana. 175 participantes declararam ter sido diagnosticado com alguma IST no último ano, porém, o estudo não discriminou quais e os valores discriminados em cada uma delas. 
De março de 2012 a outubro de 2014, Kuhns, et al. (2015) realizou uma coorte em três cidades dos Estados Unidos. Participaram do estudo 180 mulheres trans jovens de cor negra, baixo status econômico e com média de idade de 23.4 anos, recrutadas em comunidades transgênero distribuídas nessas cidades. Das 111 participantes elegíveis para tomarem a PrEP, 47 delas apresentaram alto interesse na profilaxia. Não foram relatadas ISTs entre as participantes.

Morgan, et al. (2018) promoveu um estudo de coorte de 2015 a 2017 na cidade de Chicago, incluindo 472 HSH e mulheres trans jovens, com média de idade de 20.8 anos. Os participantes foram recrutados por meio de mídias sociais e estratégia "bola de neve". Entre os participantes, 21,3\% relatou ter feito uso regular da PrEP nos últimos 6 meses.

A coorte realizada por Koss, et al. (2017) englobou 247 HSH de 15 a 22 anos de idade. A adesão à profilaxia nos envolvidos foi avaliada por meio de quatro métodos diferentes: auto-declaração, abertura do frasco inteligente, concentração do fármaco no cabelo e teste em gota de sangue. Ao final das 48 semanas de estudo, cerca de $30 \%$ dos participantes haviam concentração plasmática da substância correspondente à ingestão de 4 ou mais comprimidos de PrEP por semana. Não foram relatadas intercorrências no decorrer do estudo.

Daughtridge, et al. (2014) promoveu um estudo de coorte de fevereiro a setembro de 2013 na Filadélfia, com a participação de 23 HSH negros com média de idade de 21 anos. Esses jovens eram acompanhados semanalmente, no momento de retirada da quantidade de pílulas da semana seguinte. Entre os participantes, somente 2 completaram as vinte e oito semanas de acompanhamento, correspondendo a uma taxa de $8,7 \%$ do público participante. Durante o programa, foram relatados 4 casos de infecções sexualmente transmissíveis, sendo 3 deles causados por clamídia e 1 por gonorreia.

Cinco trabalhos analisados não apresentaram baixa adesão a PrEP, sendo: Baker (2017), Wood (2019), Hosek (2013), Seekaew (2019) e Hosek (2017). Nesses estudos, a eficácia da PrEP apresentou valores baixos, variando de 36 a 61\%. Contudo, a maioria dos estudos classificados nesse grupo foram de natureza coorte, sofrendo maior influência de questões ligadas ao paciente, como falha de tomada a longo prazo, doses perdidas e abandono de tratamento, não refletindo necessariamente baixa eficácia do fármaco ou no protocolo da profilaxia.

Os estudos realizados por Kunhs (2015), Wood (2017) e Koss (2017) não apresentaram associação entre a adesão de PrEP e a infecção por HIV. Dessa forma, o risco era igual entre as pessoas que faziam uso de PrEP comparado com aquelas que não faziam. 
Vale ressaltar que dois desses estudos foram realizados com a participação de mulheres transexuais, o que fomenta a necessidade de maior divulgação da PrEP nesse público e avaliação das estratégias atuais para alcançá-lo.

A infecção pelo vírus passou por um processo de "juvenização", aumentando a porcentagem de jovens na faixa de 17 a 20 anos, assim como no público feminino. Com isso, tornou-se necessário elaborar métodos de busca ativa por essas pessoas por meio de redes sociais, redes de contato e não apenas no espaço confinado de um serviço de saúde circunscrito. Tal plano adotado mostra resultados positivos quando, para além da busca pela TARV após a infecção, a média de idade dos participantes dos estudos incluídos nessa revisão foi de 20.2 anos. Ademais, os estudos realizados evidenciam um crescimento substancial na taxa de adesão ao medicamento, passando de aproximadamente $10 \%$ do público avaliado no ano de 2012 e nos próximos seguintes para cerca de $25 \%$ a partir do ano de 2015, chegando a ultrapassar os 50\% nos estudos do ano de 2019 incluídos nessa revisão, apesar da baixa taxa de prevalência total nos estudos incluídos, correspondendo a $29 \%$ do público total.

Apesar dessa mudança de comportamento, ainda existem dificuldades relacionadas à adesão à PrEP por parte de seus usuários. No Brasil, a principal dificuldade encontrada é a falta de informações aprofundadas sobre o tema, uma vez que o medicamento começou a ser distribuído apenas em dezembro de 2017, e parcela da população jovem ainda não possui informações sobre acesso, uso e possíveis efeitos colaterais da profilaxia. Paralelamente a isso, o estigma criado a partir da epidemia internacional de HIV/AIDS iniciada na década de 80 ao redor das pessoas vivendo com HIV/AIDS (PVHA) persiste até os dias de hoje, atingindo também aqueles que buscam estratégias de, em primeiro plano, evitar a infecção pelo vírus, como aqueles que fazem uso da PrEP.

O pré-conceito ao redor do HIV ou da pessoa vivendo com ele ${ }^{[41]}$ teve início nos próprios serviços de saúde ${ }^{[42,43]}$, os quais propagavam a ideia de uma ameaça invisível que se alastrava sem meio definido de contágio, levando à categorização dessas pessoas nos chamados "grupos de risco". Ainda nos dias de hoje, aproximadamente 40 anos depois da epidemia inicial, esse conceito permanece ativo, atingindo os $\mathrm{HSH}$, travestis, transexuais, profissionais do sexo e usuários de drogas recreativas, fazendo com que a busca dessas pessoas por serviços e estratégias promovidas pelas políticas públicas de saúde seja reduzida.

Além dos serviços de saúde, existe o estigma social presente na realidade das pessoas vivendo nos chamados "grupos de risco", excluindo ainda mais essas pessoas do convívio em sociedade por meio de criminalização dos seus comportamentos sexuais e afetivos, 
desqualificando os mesmos e alimentando um quadro de pânico moral já existente ${ }^{[44]}$, além de fragilizar ainda mais relações interpessoais. Isso se dá principalmente pelo alimento da ideia de que as pessoas pertencentes a esse grupo e aquelas que fazem uso da profilaxia são reprodutoras incessantes de comportamentos promíscuos, refletidos na multiplicidade de parceiros, imoralidade e disseminação de infecções sexualmente transmissíveis no meio os quais fazem parte.

No estudo realizado, não foram observadas relações estatisticamente significantes entre o uso de PrEP e o aumento de outras ISTs além do HIV. Nos trabalhos incluídos nesta análise, ocorreram casos de infecção por outras ISTs nos pacientes que utilizavam a PrEP, contudo, foram relatados apenas 33 casos de clamídia de 1 caso de gonorreia, fazendo com que a clamídia, infecção mais prevalente, atingisse somente $1 \%$ dos indivíduos acompanhados. Contudo, torna-se precipitado associar o acometimento por clamídia, gonorreia ou outras ISTs ao uso exclusivo da PrEP, uma vez que há uma tendência histórica preexistente entre jovens de 13 a 24 anos ao uso irregular do preservativo ${ }^{[30,21]}$, variando desde a inutilização completa (por fatores relacionados ao parceiro, fatores externos ou pessoais) até o uso descontinuado dessa forma de proteção com parceiro estável ou eventual $^{[22]}$, apesar das diferentes estratégias de educação sexual disponíveis nos vários países, o que inclui a distribuição gratuita de materiais como preservativos e lubrificantes como é realizada no Brasil ${ }^{[45]}$.

Diante do exposto, torna-se necessária a incorporação da mudança de conceito e de atitude nos diferentes meios sociais, alterando o conceito de "grupo de risco" ou "grupo vulnerável" para "comportamento de risco" ou "comportamento de experimentação arriscada com sentimento de invulnerabilidade" ${ }^{[46,47]}$, visando diminuir os comportamentos de exposição como o uso inconsistente do preservativo, relações sexuais sob efeito de álcool ou outras substâncias ou parceiro(a) sexual pouco ou recém-conhecido ${ }^{[48]}$, favorecendo a diminuição das taxas de infecção, transmissão vertical e o aumento as taxas de tratamento e prevenção continuada, como a PrEP, para níveis efetivos. 


\section{CONCLUSÃO}

A Profilaxia Pré-Exposição (PrEP) figura como nova estratégia de prevenção do HIV desde sua aprovação, em 2012, como forma de tentar diminuir as taxas de infecção em indivíduos-chave, como HSH, travestis, transexuais, profissionais do sexo e usuários de drogas recreativas. Parte desses indivíduos se localiza na população jovem, de 15 a 24 anos, figurando com altos índices de infecção pelo HIV no meio internacional.

Por meio deste estudo, evidenciou-se aumento nas taxas de adesão à profilaxia por parte do público jovem, especialmente entre os HSH de 20 anos de idade, em médias, apesar de alguns fatores sociais, como a etnia, não terem mostrado influência direta nas estatísticas de adesão à PREP. Além disso, não é possível inferir que a forma de terapia combinada adotando a PrEP seja responsável pelo aumento do número de outras ISTs que não o HIV, pois o uso dessa estratégia de prevenção do HIV contribui para a retenção de jovens e adolescentes em serviços de cuidado à saúde. Desta forma, este estudo se torna relevante ao possibilitar o registro de um panorama atual do uso da PrEP ao HIV e a resposta de diferentes grupos sociais a essas estratégias. 


\section{REFERÊNCIAS BIBLIOGRÁFICAS}

1. Melhuish A, Lewthwaite P. Natural history of HIV and AIDS. Medicine Journal. June 2018, 46(6), 356-61.

2. Sharp PM, Hahn BH. Origins of HIV and AIDS Pandemic. Cold Spring Harb Perspective Med. 2011, 1(1), a006841.

3. Moss AR, Bacchetti P. Natural history of HIV infection. AIDS. 1989, 3, 55-61.

4. Maartens G, Celum C, Lewin SR. HIV infection: epidemiology, pathogenesis, treatment, and prevention. Lancet. 2014, 384, 258-71.

5. Simon D, et al. Prevalência de subtipos do HIV-1 em amostra de pacientes de um centro urbano no sul do Brasil. Rev. Saúde Pública [online]. 2010, 44(6), 1094-1101.

6. Pinto ACS, Pinheiro PNC, Vieira NFC, Alves MDS. Compreensão da pandemia da AIDS nos últimos 25 anos. Jornal Brasileiro de Doenças Sexualmente Transmissíveis. 2007, 19(1), 45-50.

7. Hemelaar J. The origin and diversity of the HIV-1 pandemic. Trends in Molecular Medicine. 2012, 18(3), 182-192.

8. Riedel M, Ribas JLC. Prevalência de subtipos de HIV-1 no Brasil: uma revisão. Caderno de Saúde e Desenvolvimento. 2015, 7(4), 91-103.

9. GRMEK M. O enigma do aparecimento da AIDS. Estudos Avançados. 1995, 9(24), 22939.

10. Freed EO. HIV-1 Replication. Somatic Cell and Molecular Genetics. 2001, 26(1-6), 13 33.

11. Gelderblom HR, Ozel M, Pauli G. Morphogenesis and morphology of HIV: Structure function relations. Arch Virol. 1989, 106(1-2), 1-13.

12. Fanales-Belasio E, Raimondo M, Suligoi B, Buttò S. HIV virology and pathogenetic mechanisms of infection: a brief overview. Ann Ist Super Sanita. 2010, 46(1), 5-14.

13. Nyamweya M, et al. Comparing HIV-1 and HIV-2 infection: Lessons for viral immunopathogenesis. Rev. Med. Virol. 2013, 23, 221-240.

14. Esbjornsson J, et al. Inhibition of HIV-1 Disease Progression by Contemporaneous HIV2 Infection. N Engl J Med. 2012, 367, 224-232.

15. Popper SJ, et al. Lower Human Immunodeficiency Virus (HIV) Type 2 Viral Load Reflects the Difference in Pathogenicity of HIV-1 and HIV-2. The Journal of Infectious Diseases. 1999, 180, 1116-21. 
16. Swarcwald CL, Bastos FI, Esteves MAP, Andrade CLT. A disseminação da epidemia da AIDS no Brasil, no período de 1987-1996: uma análise espacial. Cadernos de Saúde Pública. 2000; 16(1): 7-19.

17. Brito AM, Castilho EA, Swarcwald CL. AIDS e infecção pelo HIV no Brasil: uma epidemia multifacetada. Revista da Sociedade Brasileira de Medicina Tropical. 2000; 34(2): 207-217.

18. Silva RAR, Duarte FHS, Nelson ARC, Holanda JRR. A epidemia da AIDS no Brasil: Análise do perfil atual. Revista de enfermagem UFPE online. 2013, 7(10), 6039-46.

19. Amaral RS. Adolescência, juventude e HIV/AIDS: estudo de fatores associados [dissertação]. Universidade Ceuma, 2016.

20.Taquette, SR. HIV/ Aids among adolescents in Brazil and France: similarities and differences. Saude soc. [online]. 2013, 22(2), 618-628.

21. Brasil. Boletim Epidemiológico HIV/AIDS. 2012.

22. Pereira BS, et al. Fatores associados à infecção pelo HIV/AIDS entre adolescentes e adultos jovens matriculados em Centro de Testagem e Aconselhamento no Estado da Bahia, Brasil. Ciênc. saúde coletiva [online]. 2014, 19(3), 747-758.

23. Villarinho MV, et al. Políticas públicas de saúde face à epidemia da AIDS e a assistência às pessoas com a doença. Rev. bras. enferm. 2013, 66(2), 271-277.

24. Pinheiro CVQ, Medeiros NM. Práticas de prevenção do HIV/Aids e modos de subjetivação. Revista de Saúde Coletiva. 2013, 23(2), 629-646.

25. Dourado I, Veras MASM, Barreira D, Brito AM. Tendências da epidemia de Aids no Brasil após a terapia anti-retroviral. Rev Saúde Pública. 2006, 40, 9-17.

26. Galvão J. A política brasileira de distribuição e produção de medicamentos antiretrovirais: privilégio ou um direito?. Cad. Saúde Pública. 2002, 18(1), 213-219.

27. Kramer AS, Lazzarotto AR, Sprinz E, Manfroni WC. Alterações Metabólicas, Terapia Antirretroviral e doença Cardiovascular em idosos Portadores de HIV. Arq. Bras. Cardiol. 2009, 93(5), 561-568.

28. Silveira AA. Mapeamento Genético do HIV-1 e Análise de Resistências Associadas aos Antirretrovirais em Pacientes do Centro-Oeste Brasileiro [tese de doutorado]. Universidade Federal de Goiás; 2011.

29. Sales WB, et al. Comportamento sexual de risco e conhecimento sobre IST/SIDA em universitários da saúde. Revista de Enfermagem Referência. 2016, 10, 19-27. 
30. Neto AB, Araújo AC, Doher MP, Haddad MA. Revisão sobre a eficácia do preservativo em relação à proteção contra doenças sexualmente transmissíveis e gestação. Diagnóstico e Tratamento. 2009, 14(3), 123-125.

31. UNAIDS. 90-90-90: Uma meta ambiciosa de tratamento para contribuir com o fim da epidemia de AIDS. 2015, 1-38.

32. Levi J, et al. Can the UNAIDS 90-90-90 target be achieved? A systematic analysis of national HIV treatment cascades. BMJ Glob Health. 2016, 1, 1-10.

33. Marmelo AFP. PrEP (Profilaxia Pré-Exposição) no HIV: perspetivas atuais e futuras [dissertação de mestrado]. Universidade do Algarve; 2017.

34. Blumenthal J, Haubrich R. Pre-exposure Prophylaxis (PrEP) for HIV Infection: How Antiretroviral Pharmacology helps to Monitor and Improve Adherence. Expert Opin. Pharmacother., 2013, 14(13), 1777-1785.

35. Peçanha EP, Antunes OAC, Tanuri A. Estratégias farmacológicas para a terapia antiAIDS. Quim. Nova. 2002, 25(6), 1108-1116.

36. Valente AMM, Reis AF, Machado DM, Succi RCM, Chacra AR. Alterações Metabólicas da Síndrome Lipodistrófica do HIV. Arq. Bras. Endocrinol. Metab. 2005, 49(6), 871-881.

37. Batista AT. Prevenir ou remediar? Atitudes dos profissionais de saúde frente à Profilaxia Pré-Exposição ao HIV/AIDS [dissertação]. Universidade Federal da Paraíba, 2017.

38. Silva RATML. Diversidade e liberdade sexual: Defensoria Pública, movimentos sociais e a PrEP no SUS. Serv. Soc. Soc., 2018, 132, 346-361.

39. Cezar VM, Draganov PB. A História e as Políticas Públicas do HIV no Brasil sob uma Visão Bioética. Ensaios Cienc., Cienc. Biol. Agrar. Saúde. 2014, 18(3), 151-156.

40. Zucchi EM, et al. Da evidência à ação: desafios do Sistema Único de Saúde para ofertar a profilaxia pré-exposição sexual (PrEP) ao HIV às pessoas em maior vulnerabilidade. Cad. Saúde Pública. 2018; 34(7), 1-16.

41. Parker R. Estigmas do HIV/aids: novas identidades e tratamentos em permanentes sistemas de exclusão. Revista Eletrônica de Comunicação, Informação e Inovação em Saúde. 2019, 13(3), 618-633.

42. Discacciati JAC, Vilaça EL. Atendimento odontológico ao portador do HIV: medo, preconceito e ética profissional. Rev. Panam. Salud Publica/Pan Am. J. Public Health; 2001, 9(4), 234-239.

43. Teto Jr. V. Homossexualidade e saúde: desafios para a terceira década de epidemia de HIV/AIDS. Horizontes Antropológicos. 2002, 17, 147-158. 
44. Pelúcio L. Ativismo soropositivo: a politização da AIDS. Ilha. Revista de Antropologia. 2009, 9, 119-140.

45. Dourado I, MacCarthy S, Reddy M, Calazans G, Gruskin S. Revisiting the use of condoms in Brazil. Rev. Bras. Epidemiol. 2015, 18(1), 63-88.

46. Griep RH, Araújo CLF, Batista SM. Comportamento de risco para a infecção pelo HIV entre adolescentes atendidos em um centro de testagem e aconselhamento em DST/aids no Município do Rio de Janeiro, Brasil. Epidemiologia e Serviços de Saúde. 2005, 14(2), 119126.

47. Camargo BV, Giacomozzi AI, Wachelke JFR, Aguiar A. Relações Amorosas, Comportamento Sexual e Vulnerabilidade de Adolescentes Afrodescendentes e Brancos em Relação ao HIV/AIDS. Saúde Soc. 2010, 19(2), p.36-50.

48. Campo-Arias A, Ceballo GA, Herazo E. Prevalência do padrão de comportamento de risco para a saúde sexual e reprodutiva em estudantes adolescentes. Revista LatinoAmericana de Enfermagem. 2010, 18(2), 170-174. 